How to cite this article:

Al Mekhlafi, A. M., \& Tahir Osman, M. E. (2019). The effect of a holistic school improvement model in enhancing school effectiveness in Oman. Malaysian Journal of Learning and Instruction, 16(2), 187-200.

\title{
THE EFFECT OF A HOLISTIC SCHOOL IMPROVEMENT MODEL IN ENHANCING SCHOOL EFFECTIVENESS IN OMAN
}

\author{
${ }^{1}$ Abdo Mohamed Al Mekhlafi \& Mohamed El Tahir Osman \\ College of Education, Sultan Qaboos University, \\ Sultanate of Oman, Oman
}

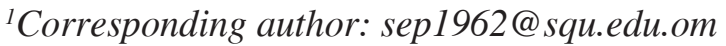

Received: 5/5/2019 Revised: 23/9/2019 Accepted: 2/10/2019 Published: 24/12.2019

\begin{abstract}
Purpose - This study examined the impact of a holistic school improvement model on overall school effectiveness, More specifically, it attempted to answer two questions: 1) Are there any significant differences in school performance between the control group and the experimental group before and after the experiment? 2 ) Is there any significant improvement in the experimental group school effectiveness before and after the experiment?

Methodology - As a part of a four-year longitudinal research project, the study used a quasi experimental research design to examine the impact of a holistic school improvement model on enhancing overall school effectiveness in Oman. The sample consisted of 16 intact classes selected from 8 schools ( 4 experimental and 4 control groups), with a total of 2378 students (1157 from grade nine classes and 1221 from grade seven classes). The experimental group schools were exposed to a wide range of school improvement activities within a four-year period. A series of workshops on activating the 13 elements of the Innovation Sustainability Wheel (ISW) were delivered to all administrators and teachers at the target experimental group schools, in addition to empowering students through enrichment programs in five subject areas. Data was collected from the Omani Ministry
\end{abstract}


of Education school performance indicators, which included five subject matter achievement tests aggregated over three years.

Findings - The study revealed significant differences in overall school performance across the four years between the control and experimental schools, in favour of the experimental group. Moreover, a significant progression of school effectiveness was observed in the two grade levels of the experimental group.

Significance - The findings are significant in terms of providing educational systems with a workable mechanism for identifying key areas of weaknesses and means of improvement; establishing a chain of actions for activating all interrelated elements that act as driving forces for sustainable change; ensuring that the indicators of school improvement should include both operational processes and students' learning outcomes; and contributing to the knowledge base in the area of school improvement in terms of a research-based model that has potential implications for practitioners and policy makers.

Keywords: School improvement, school effectiveness, systemic development, students' performance, basic education.

\section{INTRODUCTION}

Literature on school effectiveness demonstrates that context related models for educational restructuring often result in favourable changes in school functioning that lead to considerable enhancement of students' performance (City, Elmore, Fiarman, \& Teitel, 2009; Darling-Hammond, Ancess, \& Ort, 2002; Dufour, Eaker, \& DuFour, 2005; Leithwood, Day, Sammons, Harris, \& Hopkins, 2007; Stevens $\&$ Kahne, 2006). Any form of school enhancement inevitably requires the consolidated efforts of all the parties concerned in the educational spectrum and various operational plans. Moreover, achieving sustainable change that results in improving learners' academic achievement necessitates focusing on specific context related objectives and innovative plans of action.

\section{School Effectiveness}

Research into the characteristics of effective schools has identified various processes involved in school effectiveness. Scheerens 
and Bosker (1997) reviewed the constructs and instruments used in school effectiveness to collect information about school and classroom processes. Sammons, Hillman and Mortimore (1995) identified nine processes involving specific actions which are crucial for effective schools. These include processes of effective leadership, effective teaching, developing and maintaining a pervasive focus on learning, producing a positive school culture, creating high and appropriate expectations for all, emphasizing student responsibilities and rights, monitoring progress at all levels, developing staff skills at the school site, and processes of involving parents in productive and appropriate ways. In addition, Magulod (2017) presented seven factors that contribute towards making a school effective: a safe and orderly environment, a climate of high expectations for success, instructional leadership, opportunity to learn and student time on task, a clear and focused mission, frequent monitoring of student progress, and home-school relations. According to Creemers (1994), it is possible to criticize this list, and others of the same nature, on conceptual, theoretical and empirical grounds, e.g., the definition of the five factors, the location of the factors and the empirical support that these factors receive in research. This is still an issue in the recent debate on school effectiveness.

\section{School Improvement}

Many researchers agree that school improvement frameworks have the potential to provide more insight into strategies that would successfully change schools towards improved effectiveness. Hopkins (1995) suggested that it is rather obligatory to say that school effectiveness and improvement research can and should learn from each other, but the differences between the two may be so large that unlinking seems more rational. According to Schreens (1992), school effectiveness is concerned with theories and research studies on the means-ends-relationships between educational processes and outcomes, in particular student knowledge and skills in several domains, aiming at explanations for differences in student achievement between schools and classrooms. School improvement on the other hand refers to all theories and studies concerning strategies for educational change that enhances student outcomes as well as strengthening the school's capacity for managing change.

The question of how schools can become effective has often been answered in improvement projects by pointing to the role of the 
school culture. Some researchers observe that school improvement can provide an excellent opportunity for research on school effectiveness. According to Creemers and Reezigt (1997), school improvement can offer school effectiveness research and theory a very useful type of knowledge, particularly about what works in changing from ineffective to effective schools, and a natural setting to test hypotheses as well. This results in establishing stronger links between school effectiveness and school improvement. They have also identified the following stages of links between school effectiveness and school improvement:

- Phrasing the improvement problem in terms of school effectiveness;

- $\quad$ Making use of the knowledge base of school effectiveness to outline the actual contents of the improvement project;

- Design and development of a plan for action and implementation of this plan, making use of empirical evidence whenever possible;

- Implementation of the evaluation of the project;

- Discussion of the results and conclusions, not only with respect to further school improvement but also school effectiveness.

The stages outlined are based on the assumption that there is a school effectiveness knowledge base and that it can be important for school improvement. This shows clearly that school improvement is not something that starts at given period of time and comes to an end at a time set for finishing a project; instead, it is an ongoing process. In school education, the term ongoing improvement or continuous improvement indicates that the process of school improvement progressively unfolds and is sustained over a period of time. To sum up, school improvement researchers insist that school improvement is a cyclical process which should have an elaborate Plan and systematic Framework. It is also suggested that this school improvement framework should have a theoretical basis. It is clear from the studies of school improvement that school effectiveness research should strengthen school improvement plans and frameworks.

The need for enhancing the level of education in general and improving students learning potential in particular has led the Sultanate of Oman to pay considerable attention to improving the educational system in various ways. Several educational renewals, 
research-based operational initiatives and strategies have been put in place. However, it would seem that most of these initiatives have not borne sufficient fruit in terms of producing sustainability of reform due to limiting the focus on individual subsystems rather than consolidating all driving forces as a whole set of restricting elements (Al Barwani \& Osman, 2011). Therefore, as part of a large scale project, this study attempted to examine the effect of all the possible interrelated elements as a whole set in enhancing school effectiveness and optimizing students' learning in the Omani school system. Such an initiative is expected to result in sustainable improvement of the Omani school system in general and enhancement of learners' potential in particular, wherein all the interrelated elements of reform function together and reinforce each other to produce maximum results. It is hypothesized that any sustained improvement in the school system is a function of a set of interrelated driving forces or subsystems that collectively drive the overall performance of the school system, and impact students' learning potentials. Accordingly, for the purpose of this study, the Innovation Sustainability Wheel (see Figure 1) was implemented, in which interrelated driving forces are activated holistically to improve school effectiveness.

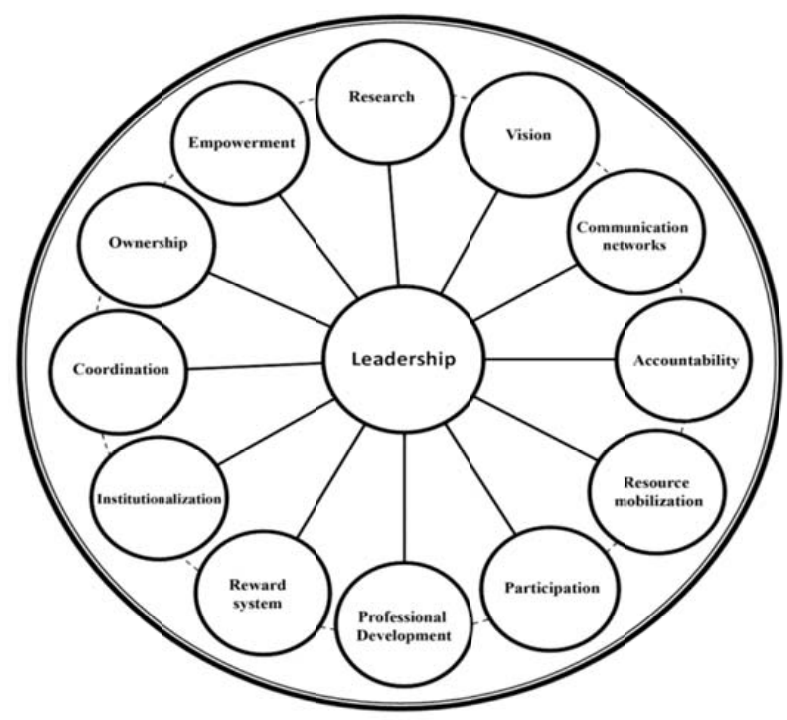

Figure 1. The Innovation Sustainability Wheel (ISW). Source: Al Barwani \& Osman (2011). 
The Innovation Sustainability Wheel (ISW) illustrates the main driving forces for sustaining educational innovations. The ISW was developed as a theoretical model to be used as a tool to analyze the fit and readiness of educational innovations, and to identify the missing links that may impact the life span and potential sustainability of any innovation. The aim of this particular study was to examine the collective impact of the proposed model (i.e., the ISW) on school effectiveness. More specifically, this study aimed to answer the following questions:

\section{Research Questions}

1. Are there any significant differences in school performance between the control group and the experimental group before and after the experiment?

2. Is there any significant improvement in the experimental group school effectiveness before and after the experiment?

\section{METHODOLOGY}

As a part of a four-year longitudinal research project, this study used a quasi experimental research design to examine the impact of a holistic school improvement model on enhancing overall school effectiveness in Oman. The sample consisted of 16 intact classes selected from 8 schools (4 experimental and 4 control groups), with a total number of 2378 students (1157 from grade nine classes, and 1221 from grade seven classes). At the end of the experiment, the experimental group schools' performance was compared with their control group schools' performance.

\section{Instruments}

The data was derived from the Omani Ministry of Education (MoE) school performance indicators, which included five subject matter achievement tests aggregated over three years. It is worth mentioning that the MoE school performance indicators were developed and validated by the MoE.

\section{Procedures}

The study used the Innovation Sustainability Wheel (ISW) as a theoretical model for a systemic enhancement of school effectiveness. 
The experimental group schools were exposed to a wide range of school improvement activities within a three-year period. A series of workshops on activating the 13 elements of the ISW were delivered to all administrators and teachers at the target experiment group schools, in addition to empowering students through enrichment programs in five subject areas. For example, both experimental group teachers and students were furnished with an interactive e-learning platform of e-content and other open sources in the five subject areas (Science, Mathematics, English Language, Arabic Language, and Information Technology).

All the interventions were geared towards enhancing learning environments that would provide students with various opportunities for more engagement in meaningful learning, e.g., inquiry, projectbased learning, self-regulatory activities, reflection and exploration, online collaboration, and interactive instructional and learning activities. On top of all these, teachers were involved in relevant on-site professional development, and supported by supplementary online training resources. To measure post intervention outcomes, the data was collected and aggregated based on the overall students' performance in the five subject areas.

\section{RESULTS}

With regard to school effectiveness, Tables 1 and 2 exhibit the significant difference between the control group and the experimental group for grades 7 and 9 across three years.

Table 1

Pre-post Mean Differences in Grade 9 School Effectiveness between Experimental and Control Groups across Three Years

\begin{tabular}{lccccccc}
\hline \multirow{2}{*}{ Group } & & $\mathrm{N}$ & Mean & $\begin{array}{c}\text { Std. } \\
\text { Deviation }\end{array}$ & df & T & Sig. \\
\hline \multirow{2}{*}{ TOT2014 } & EXP & 621 & 68.31 & 21.28 & 1155 & .03 & .97 \\
& CONT & 536 & 68.27 & 20.81 & & & \\
\multirow{2}{*}{ TOT2016 } & EXP & 621 & 74.70 & 14.73 & & \multirow{2}{*}{2.68} & .007 \\
& CONT & 536 & 72.15 & 17.61 & & & \\
\hline
\end{tabular}


Table 1 shows the differences between the control group and the experimental group for grade 9 at the beginning of 2014, and the end of the experiment in 2016. The results reveal significant differences in school effectiveness (at 0.01 level) between the control group and the experimental group in 2016, as opposed to the level of school effectiveness in 2014 where the two groups were equivalent. The means for both experimental and control groups were similar in 2014 (68.31 and 68.27 respectively), whereas the level of difference in school effectiveness between the groups increased significantly in 2016 with a mean of 70.65 for the control group, and 73.00 for the experimental group.

Table 2

Pre-post Mean Differences in Grade 7 School Effectiveness between Experimental and Control Groups across Three Years

\begin{tabular}{cccccccc}
\hline \multirow{2}{*}{ Group } & & N & Mean & $\begin{array}{c}\text { Std. } \\
\text { Deviation }\end{array}$ & DF & T & Sig \\
\hline \multirow{2}{*}{ TOT2014 } & EXP & 618 & 55.72 & 35.60 & 1219 & -.38 & 0.70 \\
& CONT & 603 & 56.48 & 32.95 & & & \\
\multirow{2}{*}{ TOT2016 } & EXP & 618 & 72.91 & 14.03 & 1219 & 3.90 & 0.00 \\
& CONT & 603 & 69.40 & 17.30 & & & \\
\hline
\end{tabular}

Table 2 shows the differences between the control group and the experimental group for grade 7 . The results indicate no significant differences between the two groups in 2014 (at 0.05 level) with mean scores of 55.72 and 56.48 for the eexperimental and control groups, respectively. In contrast, the level of difference in school effectiveness was significant in 2016 ( $\mathrm{p}=0.00$ ) with a mean of 69.40 for the control group and 72.91 for the experimental group.

Table 3

Mean Scores of Grade 9 School Effectiveness across Three Years

\begin{tabular}{cccc}
\hline Time & N & Mean & Std. Deviation \\
\hline 2014 & 621 & 68.31 & 21.28 \\
2015 & 621 & 73.01 & 18.23 \\
2016 & 621 & 74.70 & 14.73 \\
Total & 1863 & 72.01 & 18.47 \\
\hline
\end{tabular}


Table 4

ANOVA Test for the Mean Scores of Grade 9 School Effectiveness across Three Years

\begin{tabular}{lcrrrr}
\hline & $\begin{array}{c}\text { Sum of } \\
\text { Squares }\end{array}$ & \multicolumn{1}{c}{ df } & $\begin{array}{c}\text { Mean } \\
\text { Square }\end{array}$ & F & Sig. \\
\hline Between Groups & 13620.096 & 2 & 6810.05 & 20.37 & .000 \\
Within Groups & 621815.240 & 1860 & 334.31 & & \\
Total & 635435.337 & 1862 & & & \\
\hline
\end{tabular}

Table 5

Scheffe Test for Post Hoc Analysis

\begin{tabular}{ccccc}
\hline \multirow{2}{*}{ Time } & & $\begin{array}{c}\text { Mean Difference } \\
(\mathrm{I}-\mathrm{J})\end{array}$ & Std. Error & Sig. \\
\hline \multirow{2}{*}{2014} & 2015 & $-4.69^{*}$ & 1.03 & .000 \\
& 2016 & $-6.39^{*}$ & 1.03 & .000 \\
\multirow{2}{*}{2015} & 2014 & $4.69^{*}$ & 1.03 & .000 \\
& 2016 & -1.69 & 1.03 & .263 \\
\multirow{2}{*}{2016} & 2014 & $6.39^{*}$ & 1.03 & .000 \\
& 2015 & 1.69 & 1.03 & .263 \\
\hline
\end{tabular}

With reference to question 2, i.e., examining within group differences for grade 9 between the beginning and end of the experiment, Tables 3, 4, and 5 show a relatively steady progression in overall school effectiveness across three years. As illustrated in Table 4 , the ANOVA test found a significant main effect of the treatment $(\mathrm{F}=20.37 ; \mathrm{P}=0.000)$. Moreover, as demonstrated in the Scheffe test (see Table 5), there was a significant improvement in school effectiveness (at 0.01 level) at the end of the experiment.

In addition to the relatively steady progression in school effectiveness observed in grade 9 classes, the results for grade 7 reveal a clear and significant steady progression in school effectiveness across the three years (beginning, middle, and end of experiment). As illustrated in Table 6, the ANOVA test found a significant main effect of the treatment $(\mathrm{F}=62.83 ; \mathrm{P}=0.000)$. Furthermore, the Scheffe test for 
post hoc analysis revealed significant differences between the three intermittent phases of the study at the 0.01 level.

Table 6

Mean Scores of Grade 7 School Effectiveness across Three Years

\begin{tabular}{cccc}
\hline Time & N & Mean & Std. Deviation \\
\hline 2014 & 618 & 55.73 & 35.60 \\
2015 & 618 & 65.21 & 26.90 \\
2016 & 618 & 72.92 & 14.02 \\
Total & 1854 & 64.61 & 27.89 \\
\hline
\end{tabular}

Table 7

ANOVA Test for the Mean Scores of Grade 7 School Effectiveness across Three Years

\begin{tabular}{crrrrr}
\hline & Sum of Squares & df & $\begin{array}{c}\text { Mean } \\
\text { Square }\end{array}$ & F & Sig. \\
\hline Between Groups & 91651.70 & 2 & 45825.85 & 62.8 & .000 \\
Within Groups & 1350139.27 & 1851 & 729.41 & & \\
Total & 1441790.97 & 1853 & & & \\
\hline
\end{tabular}

Table 8

Scheffe Test for Post Hoc Analysis for Grade 7 across Three Years

\begin{tabular}{lcccc}
\hline \multirow{2}{*}{ Time } & & $\begin{array}{c}\text { Mean Difference } \\
(\mathrm{I}-\mathrm{J})\end{array}$ & Std. Error & Sig. \\
\hline \multirow{2}{*}{2014} & 2015 & $-9.48^{*}$ & 1.53 & .000 \\
& 2016 & $-17.19^{*}$ & 1.53 & .000 \\
\multirow{2}{*}{2015} & 2014 & $9.48^{*}$ & 1.53 & .000 \\
& 2016 & $-7.71^{*}$ & 1.53 & .000 \\
\multirow{2}{*}{2016} & 2014 & $17.19^{*}$ & 1.53 & .000 \\
& 2015 & $7.71^{*}$ & 1.53 & .000 \\
\hline
\end{tabular}




\section{DISCUSSION}

This study revealed significant differences in school effectiveness between the experimental and control group in favour of the experimental group, i.e., the level of school effectiveness increased significantly between 2014 and 2016. This pattern of school effectiveness was demonstrated in both grades 7 and 9. In addition to the significant improvement in the experimental group schools between the beginning and end of the three-year treatment compared with the control group schools, the analysis of the two groups' performance across the three years also showed continuous progress of the experimental group schools over that of the control group schools. In general, the findings of this study appear to be congruent with the current literature on school effectiveness (Brunings, 2014; Cowell \& Evans, 2013; Creemers \& Kyriakides, 2010; Creemers, Kyriakides, \& Antoniou, 2012; Cruddas, 2007; Ismail, 2014; Osman \& Al Mekhlafi, 2018; Tengku Ariffin, Awang-Hashim, \& Yahya, 2010). Research on school improvement models show that contextualized systemic approaches to educational reform produce positive changes in the school operational processes, which in turn, result in significant increases in school effectiveness. It also shows the importance of the effect of effective leadership, which inevitably leads to enhancing the school environment and results in raising students' achievement (Amin, Shah, \& Tatlah, 2013; Hengpiya, 2008; Osman \& Al-Mekhlafi, 2018).

\section{CONCLUSIONS AND RECOMMENDATIONS}

Based on the findings, it can be concluded that the quality of school effectiveness is deemed to happen if a holistic improvement is considered, where all the potential school effectiveness elements are systemically activated. It can also be concluded that the ISW provides a firm basis for schools to compete for excellence as educational changes and innovations occur. In summary, the driving forces of a systemic sustainability can enhance school effectiveness and promote greater overall school performance, which inevitably reflects in improvement in students' learning. Empowering teachers as agents of change requires providing them with an adequate work environment as well as opportunities to take initiative, and involving them in decision making to become responsible for their 
own progress. It is therefore recommended that each school can embed the concept of quality improvement into its own subsystems of leadership, professional development, teaching, and learning, continue to monitor student performance improvement through national as well as international testing and other performance indicators, create long term partnerships with other educational institutions to constantly support relevant research activities, and gradually transfer the responsibility of monitoring, updating and organizing e-content and enrichment material. However, for extending the landscape of the ISW internationally, further research is recommended in order to study its feasibility and effectiveness in other regional and international contexts.

\section{ACKNOWLEDGEMENT}

This study is part of a research project supported by an HM grant from Sultan Qaboos University (HM Grant\#: SR/EDU/TECH/14/01, 2014).

\section{REFERENCES}

Al Barwani, T. A., \& Osman, M. E. (2011). Promoting students learning through sustainable innovations: Where is the missing link? In J. MacBeath and T. Townsend (Eds.), International handbook on leadership for learning, 845-865. Dordrecht: Springer.

Amin, M., Shah, S., \& Tatlah, I. A. (2013). Impact of principals, directors' leadership styles on job satisfaction of the faculty members: Perceptions of the faculty members in a public university of Punjab, Pakistan. Journal of Research, 7(2), 97112.

Brunings, J. (2014). What big business can learn from a small school. Retrieved from https://onstrategyhq.com/resources/ what-big-business-can-learn-from-a-small-school/

City, E. A., Elmore, R. F., Fiarman, S. E., \& Teitel, L. (2009). Instructional rounds in education: A network approach to improving teaching and learning. Cambridge, MA: Harvard Education Press. 
Cowell, N., \& Evans, M. J. (2013). Real school improvement: is it in the eye of the beholder? Educational Psychology in Practice: Theory, Research and Practice in Educational Psychology, 29(3), 219-242. doi:10.1080/02667363.2013.798720

Creemers, B. P. M., \& Kyriakides, L. (2010). School factors explaining achievement on cognitive and affective outcomes: Establishing a dynamic model of educational effectiveness. Scandinavian Journal of Educational Research, 54(3), 263294. doi:10.1080/00313831003764529

Creemers, B. P. M., Kyriakides, L., \& Antoniou, P. (2012). A dynamic approach to school improvement: Main features and impact. School Leadership \& Management, 33(2), 114-132. doi:10.1080/13632434.2013.773883

Creemers, B. P. M. (1994). The effective classroom. London: Cassell. Creemers, B. P. M., \& Reezigt, G. J. (1997). School effectiveness and school improvement: Sustaining links. School Effectiveness and School Improvement, 8(4), 396-429.

Crowley, J. J., \& Hauser, A. G. (2007). Evaluating whole school improvement models: Creating meaningful and reasonable standards of review. Journal of Education for Students Placed on Risk (JESPAR), 12(1), 37-58. doi:10.1080/10824660701247242

Cruddas, L. (2007). Engaged voices - Dialogic interaction and the construction of shared social meanings. Educational Action Research, 15(3), 479-88.

Darling-Hammond, L., Ancess, J., \& Ort, S. W. (2002). Reinventing high school: Outcomes of the coalition campus school project. American Educational Research Journal, 39, 639-673.

DuFour, R., Eaker, R., \& DuFour, R. (Eds.). (2005). On common ground: The power of professional learning communities. Bloomington, IN: Solution Tree.

Magulod, G. C. Jr. (2017). Factors of school effectiveness and performance of selected public and private elementary schools: Implications on educational planning in the Philippines. Asia Pacific Journal of Multidisciplinary Research, 5(1), 73-83.

Hengpiya, A. (2008). Construct validity of a school principal decision-making styles scale. Malaysian Journal of Learning \& Instruction, 5, 41-61.

Hopkins, D. (1995). Towards a theory for school improvement. Paper presented to the ESRC 
Seminar series on School Effectiveness and School Improvement, Newcastle University. October 1994.

Hoque, K. E. (2009). Leadership and school culture in primary cluster schools. Malaysian Online Journal of Educational Management (MOJEM), 5(4), 18-34.

Ismail, S. N. (2014). Total quality management (TQM) practices and school climate amongst high, average and low performance secondary schools. Malaysian Journal of Learning \& Instruction, 11, 41-58.

King, K. (2009). Education, skills, sustainability and growth: Complex relations. International Journal of Educational Development, 29, 175-181.

Leithwood, K., Day, C., Sammons, P., Harris, A., \& Hopkins, D. (2007). Seven strong claims about successful school leadership. London: Department for Education and Skills.

Osman, M., \& Al Mekhlafi, A. (2018). The impact of a systemic innovation sustainability model on students' academic performance in Oman. International Journal of Education, 10(1), 125-139.

Sammons, P., Hillman, J., \& Mortimore, P. (1995). Key characteristics of effective schools: A review of school effectiveness research. London: Institute of Education.

Scheerens, J. (1992). Effective schooling: Research, theory and practice, London: Cassell.

Scheerens, J., \& Bosker, R. J. (1997). The foundations of educational effectiveness. Seminar series on School Effectiveness and School Improvement, Newcastle University. October 1994.

Stevens, W. D., \& Kahne, J. (2006). Professional communities and instructional improvement practices: A study of small high schools in Chicago. University of Chicago Consortium on Chicago School Research. Chicago, IL:The Free Press.

Tengku Ariffin, T. F., Awang-Hashim, R., \& Yahya, K. K. (2010). Modeling the relationships between personality factors, perceptions of the school as a learning organization and workplace learning of school teachers. Malaysian Journal of Learning \& Instruction, 7, 15-35. 